This item was submitted to Loughborough's Research Repository by the author.

Items in Figshare are protected by copyright, with all rights reserved, unless otherwise indicated.

\title{
How to manufacture a sustainable future for 9 billion people in 2050
}

PLEASE CITE THE PUBLISHED VERSION

https://doi.org/10.1007/978-981-4451-48-2_1

PUBLISHER

(C) Springer

VERSION

AM (Accepted Manuscript)

LICENCE

CC BY-NC-ND 4.0

REPOSITORY RECORD

Rahimifard, Shahin, Leila Sheldrick, Elliot Woolley, James Colwill, and Madhu Sachidananda. 2019. "How to Manufacture a Sustainable Future for 9 Billion People in 2050". figshare. https://hdl.handle.net/2134/13299. 
This item was submitted to Loughborough's Institutional Repository (https://dspace.lboro.ac.uk/) by the author and is made available under the following Creative Commons Licence conditions.

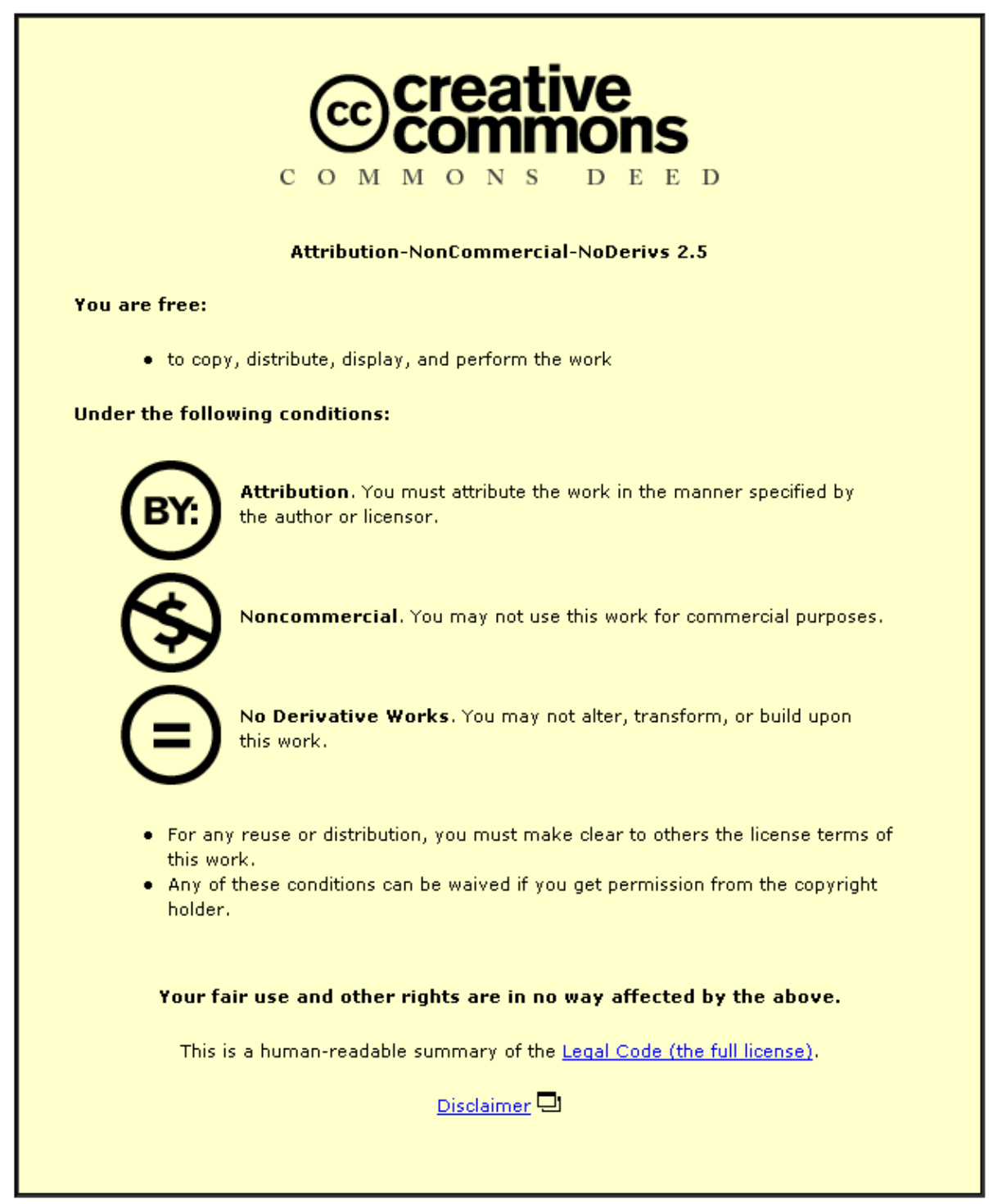

For the full text of this licence, please go to: http://creativecommons.org/licenses/by-nc-nd/2.5/ 


\title{
How to Manufacture a Sustainable Future for 9 Billion People in 2050
}

\author{
S. Rahimifard ${ }^{1}$, L. Sheldrick ${ }^{1}$, E. Woolley ${ }^{1}$, J. Colwill $^{1}$, M. Sachidananda ${ }^{1}$ \\ ${ }^{1}$ Centre for Sustainable Manufacturing and Recycling Technologies (SMART), \\ Loughborough University, UK
}

\begin{abstract}
There is a growing body of evidence which increasingly points to serious and irreversible ecological consequences if current unsustainable manufacturing practices and consumption patterns continue. Recent years have seen a rising awareness leading to the generation of both national and international regulations, resulting in modest improvements in manufacturing practices. These incremental changes however are not making the necessary progress towards eliminating or even reversing the environmental impacts of global industry. Therefore, a fundamental research question is: 'How can we meet the long term demand of our growing global population, and in this context, what are the key challenges for the future of manufacturing industry?' A common approach adopted in such cases is to utilise foresighting exercises to develop a number of alternative future scenarios to aid with long-term strategic planning. This paper presents the results of one such study to create a set of 'SMART Manufacturing Scenarios' for 2050.
\end{abstract}

\section{Keywords:}

Foresighting; Strategic Planning; Future Manufacturing Scenarios

\section{INTRODUCTION}

Our society and environment are changing at an unprecedented rate. Rapid industrial development and economic growth, brought on by staggering advancements in technology, are taking place at the expense of the environment. As we come to understand more about the biophysical constraints of our planet and the impacts of human activities, the growing scale of the challenge ahead is becoming clear.

In particular, the impact of manufacturing activities on the environment has become an area of great focus and concern at all levels, from public through to industry and government. A range of initiatives, investments and regulations have been put in place to mitigate the effects of manufacturing activities, however, at present these are at best just managing to slow down the rate of growth in environmental impact, as opposed to eliminating or reversing the damages caused.

In this context, a great deal of work has been conducted in recent years to better understand the future global requirements. It has been estimated that by 2050 the global population will have risen to over 9 billion [1] and that greenhouse gas (GHG) emissions will have increased by over $50 \%$, driven primarily by a projected $80 \%$ rise in global energy demand [2]. When considering that we need to reduce our GHG emissions by $80 \%$ (compared to 1990 levels) in order to limit global warming to a maximum increase of $2^{\circ} \mathrm{C}$ [3], this predicted rapid increase in future emissions presents serious economic and ecological concerns that require immediate attention.

Furthermore, studies have shown that if everyone in the world consumed at the rate of the average U.S. resident, we would need the resources of 4.5 Earths to sustain this [4] and the world's proven oil reserves would be consumed in less than 10 years [3]. It has also been predicted that current reserves of copper, zinc, lead, nickel, tin, silver, and gold will be depleted by 2050 [5], and a study by Gardner-Outlaw and Engleman [6] states that by 2050 up to 4 billion people could live in areas facing water scarcity or stress.

These predictions give a clear indication that current efforts to reduce impacts are not enough and therefore a radical new approach is needed; as depicted in Figure 1. In order to identify such radical improvements, foresighting and scenario planning approaches are often used by both commercial and governmental organisations to generate strategic insights. In times of high uncertainty, these methods help to understand the challenges and opportunities which lie ahead by enabling complex future scenarios to be visualised through the combination of two key facets, i.e. facts and perceptions [7].

By considering both quantitative and qualitative factors, scenario planning methods go beyond the reach of conventional planning to give a fresh, in-depth perspective. These approaches can be used by companies to systematically identify the most influential factors affecting their industry, and to explore corresponding critical change drivers through informed long term strategic planning activities.

This paper describes one such scenario planning study undertaken with a specific focus on the manufacturing industry. The first part discusses a number of existing foresighting applications and describes the methodology used to generate the 'SMART Manufacturing Scenarios' (SMS). The main section provides an overview of the critical drivers which will shape future industry, and utilises a target year of 2050 to identify four feasible scenarios for future manufacturing.

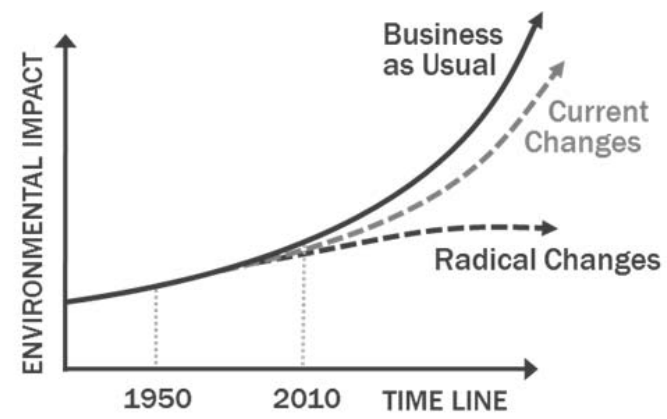

Figure 1: Environmental Impacts Projections 


\section{SCENARIO PLANNING IN PRACTICE}

Developed in the middle of the twentieth century, scenario planning was firmly established in the corporate world as a 'strategic planning tool' at Royal Dutch Shell by Pierre Wack [8] who stated:

"Scenario planning aims to rediscover the original entrepreneurial power of foresight in contexts of change, complexity, and uncertainty. It is precisely in these contexts - not in stable times - that the real opportunities lie to gain competitive advantage through strategy."

To this day, Shell remains world leader in developing scenarios and continues to offer advice to others who wish to conduct their own studies [9]. Their most recent forecasts discuss the effects of governmental and social behaviours on energy supply and put forward two opposing future scenarios [10]. These are utilised internally by viewing each through a set of 'lenses' which consist of different 'recession and recovery' outlooks based on the effects of the recent global economic crisis. This helps them to be more responsive to change in an uncertain market by accounting for, not only the key drivers directly affecting their industry, but also for globally uncertain factors.

The precedent set by Pierre Wack and Shell has seen a broad uptake of scenario planning activities in recent years. As environmental issues have become a key area of concern and future challenges have become more complex, these methods have been employed by governments and businesses alike to plan for the future, with a particular focus on 2050 as a key milestone year for society's progress. In this context, early examples of these studies were published by organisations such as the World Business Council for Sustainable Development (WBCSD) [11], the World Energy Council (WEC) [12], and the UK Department of Trade and Industry (DTI) [13] amongst others, as a means to identify critical factors which might influence progress in different areas.

More recently, a number of examples have been published through collaborative projects involving a range of stake holders such as consumers, industrial corporations and governing bodies. One such study was conducted through the 'Centre on Sustainable Consumption and Production' (CSCP), a joint venture between the United Nations Environment Program (UNEP) and the Wuppertal Institute in Germany [14]. This project created different 'SPREAD' scenarios for 2050 and used them to generate accompanying roadmaps to sustainable lifestyles in each possible future.

Another group of studies has been conducted by 'Forum for the Future' in partnership with Hewlett Packard Labs, Sony and a number of others. These projects explored different 'Climate Futures' scenarios [15] based on varying responses to climate change, and used these to facilitate crowd sourced discussions about how technology can be leveraged to help guide towards more sustainable lives in the future [16].

In each case stated above, scenario planning methodologies were used to identify the 'critical uncertainties' of each situation. These were then mapped onto two critical axes which allow four contrasting scenarios to be generated. This approach, made famous by Shell and sometimes referred to as the 'two axes method', is one of the most common outputs of these foresighting exercises [17]. It allows organisations to critically assess both quantitative and qualitative information in order to imagine possible futures in specific areas of industry, based on specific drivers and concerns. This offers the flexibility to focus on a broad, or more narrow range of influencing factors, depending on differing strategic concerns.

In this context, one such study was found which related directly to the manufacturing industry. This was conducted by the European Commission (EC) in 2003 and generated a set of 'Scenarios on the future of manufacturing in Europe 2015-2020' (FutMan) which focused on the challenges set by sustainability, and the effects of socio-economic developments and future technologies on the European manufacturing sector [18]. The project discussed various policy and market concerns as drivers for governance decisions and found that the most critical factors affecting the future of manufacturing were 'Integration of Sustainable Development Policies', and 'Public Values and Consumer Behaviour'. The scenarios generated are shown in Figure 2. This study intended to highlight key trends in European manufacturing and to stimulate thinking on policy and technological options by focussing the formation of the scenarios around ten critical socio-economic factors: Global Governance, EU (European Union) Policy Integration, Public Values (consumer behaviour), Innovation Policy, Transport/Energy Infrastructure, Sustainable Development, Education System, Higher Education, Labour Market and Social Security (labour costs).

It should be noted that although the different examples presented above were each developed with a very specific purpose and very specific audience in mind, a clear set of common themes can be observed. The recurring critical factors in each case were often found to be governmental strategies, technological advances and social values. As such, these themes have been explored further as part of the development of the SMS for 2050

\section{DEVELOPING THE SMART MANUFACTURING SCENARIOS}

A two axes scenario planning methodology was employed in this study to generate the four SMS. This method required a systematic approach to identify and assess the most critical factors affecting the development of the manufacturing industry over the next four decades with the aim of better understanding possible futures and supporting a range of strategic decisions related to design of future products, development of the next generation of production technologies and a responsible approach to business planning.

The initial stages of the study identified population growth (human impacts), climate change (ecological impacts) and resource depletion (manufacturing impacts) as the three key drivers affecting the environment and the future of manufacturing, depicted in Figure 3. For each of these drivers a range of interdependent and interlocking issues were investigated and analysed in order to identify how they might influence the future of society, governance, and therefore, the manufacturing industry.

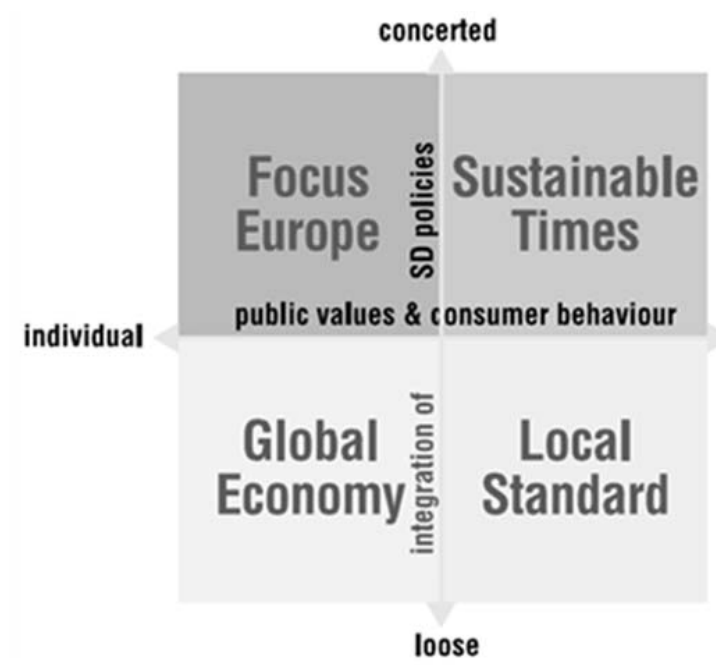

collective

Figure 2: EC Scenarios for European Manufacturing 2015-2020 [18] 


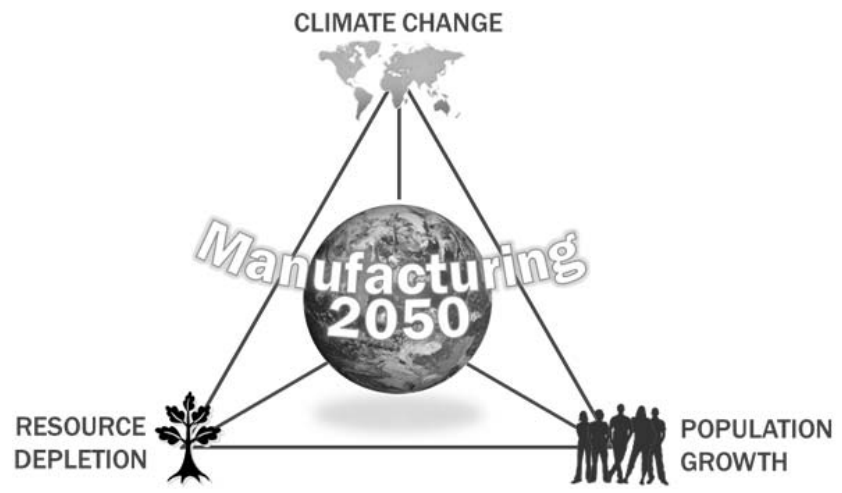

Figure 3: The Critical SMART Manufacturing Factors

\subsection{Population Growth}

Human population growth is one of the influential factors affecting the ecosystem, and as global population rises, so does the cumulative impact on the planet. As such, a better understanding of the key issues and global variations in population growth will be required to build a complete picture of the impact of this change driver for the future of the manufacturing industry, and therefore the following four thematic issues related to population growth have been considered.

\section{Rapid Rise of Global Population}

Over the last century, global population has quadrupled to a current level of over 7 billion people [19]. Although this rate of increase is expected to slow as fertility rates fall, it is estimated that the global population will surpass 9 billion people by 2050, and exceed 10 billion by 2100 [1]. More importantly, these studies also show that populations in developed countries are set to fall, or at best remain constant supported by steady migration from developing countries. This highlights that almost all of the projected population growth will occur in developing countries, as shown in Figure 4, and as the people living in these areas strive to obtain the lifestyle of the remaining population residing in developed regions, the overall global consumption is set to significantly increase. This presents one of the most significant concerns regarding the level of manufacturing outputs which will be required to meet global demand by 2050 .

\section{Shifting Global Demographics}

Studies have shown that in 2011, the median age for people living in developed countries was 39.9 , whilst for people in developing countries it was just 27.2 years [1]. Over the next four decades, it is projected that the overall global population will age with the percentage of persons over 60 years old increasing by almost $9 \%$, and while the current trend in ageing populations is most prevalent in developed countries, in the future it is expected that populations in developing countries will also begin to age, with the median age in these countries rising at a much faster rate [1]. This will clearly have a significant influence on the range, type, nature and market for specially designed products manufactured to suit the specific needs of aging population in 2050.

\section{Geographic Distribution of Populations}

For a number of years, urban populations have been growing rapidly and it is expected that this will almost double by 2050 , accounting for $70 \%$ of the global population [19]. This will have a substantial effect on required infrastructures, availability of resources, patterns in distribution and consumption, and localised ecological impacts (waste and emissions), as well as a significant, albeit indirect impact on agricultural activities [2]. The other notable consideration regarding the distribution of global populations is the effect of climate change on habitable areas and arable lands which undoubtedly affect our ability to feed the growing population. In 2009, the Food and Agriculture Organization (FAO) of the United Nations (UN) stated that over 1 billion people were already suffering severe food shortage in 37 countries worldwide [21], which is an indicative example of the ever increasing challenges for the manufacturing industry to meet the basic needs of the global population in 2050 .

\section{Access to Labour and Skills}

The proportion of the global population who are of working age has increased by $40 \%$ over the last 20 years [1], with most of this growth occurring in developing countries which now contain $85 \%$ of the world's young people. This had led to a phenomenon called 'youth bulge' as persons aged 15-30 years have come to represent over $40 \%$ of the total adult population in low income countries [22], resulting in high levels of unemployment and political unrest. This problem is also being compounded by migration of more skilled workers from these areas leading to a phenomenon known as 'brain-drain', and causing social and economic tensions in both developed and developing countries alike. Recent years have also seen a growth in the number of female members of workforces as gender equality is becoming more accepted, and also an increase in older workers due to delayed retirement. These issues related to availability of labour and skills will clearly influence the geographical distribution of different types of manufacturing activities and continue to present complex challenges for future industrial organisations.

\subsection{Climate Change}

The effects of human activities on the planet can be most clearly seen in the changing global climate of recent years. These present a significant, systemic risk to the manufacturing industry, and society as a whole. Thus, there is a need for a better understanding of the various potential impacts of climate change and to investigate this driver four main thematic issues have been explored.

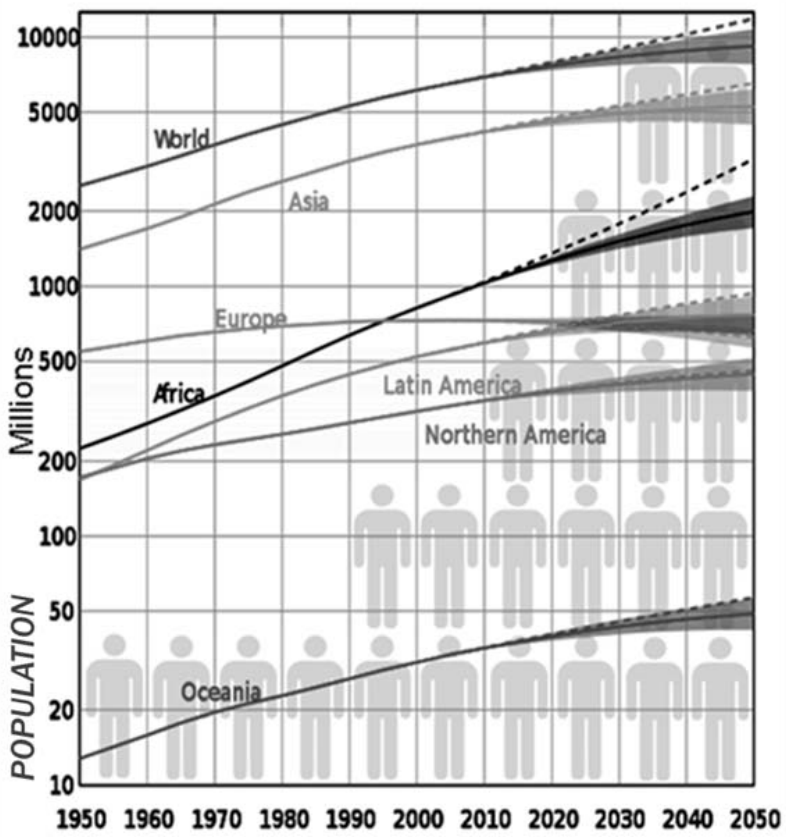

Figure 4: World Population Growth Projection. Adapted from [20] 


\section{Implications of Climate Change}

In a 'business as usual' scenario, it has been predicted that the global average temperature is likely to be $3-6{ }^{\circ} \mathrm{C}$ higher than preindustrial levels by the end of the century [2]. This would go far beyond a large number of ecological thresholds and cause dramatic, irreversible damage to a large number of natural systems seriously affecting global food production, increasing flooding, reducing freshwater supplies and resulting in substantial biodiversity losses [23]. As such, in order to mitigate these effects, the UN set a target to limit global warming to an increase of $2^{\circ} \mathrm{C}$ [24], however, even a temperature rise at this lower level will affect patterns of demands on manufactured products and access to the resources required to produce them.

\section{GHG Generation}

In order to meet the $2^{\circ} \mathrm{C}$ limit, it has been estimated that GHG emissions will need to peak in 2020 , and begin a rapid decline so that in 2050 they should be $53 \%$ lower than 2005 levels [25]. At present, the energy sector is the largest producer of GHGs, with industrial activities and transport related emissions coming in second and third place. This highlights the critical contribution of the manufacturing sector to global GHGs through direct emissions from production processes and also through indirect emissions from both consumption of non-renewable energy and excessive requirements for transportation.

\section{Environmental Legislation}

In order to enforce change and generate the radical environmental improvements needed in industrial practices, it has been widely acknowledged that holistic global policy mixes are required [2, 26] Increases in legislation however create a complex legal framework for industry to operate within, often indirectly limiting innovation, and can also be difficult even for regulators to effectively plan, monitor and enforce. Therefore, it is predicted that by 2050, the environmental regulation framework will play an even more influential role in the way that manufacturing companies can operate in different parts of the world.

\section{Economy of Climate Change}

It has commonly been reported that the benefits of strong proactive approaches to mitigate the effects of climate change will far outweigh the costs. A detailed review commissioned by the UK government entitled 'The Economics of Climate Change' [23] found that the cost of limiting global warming at $2^{\circ} \mathrm{C}$ would slow global GDP growth by only $0.2 \%$ per year, costing roughly $1 \%$ of global GDP in 2050, if early action is taken. However, the cost of inaction could amount to $5-20 \%$ of annual GDP costs, and involve much higher environmental risks [23]. The report also suggested that the costs of adverse weather effects such as flood damage, or loss of crops could have substantial impacts on global markets, for example, a $5-10 \%$ increase in hurricane wind speed has the potential to double associated damage costs in the U.S. This not only highlights the benefit of a proactive approach, but also signifies the insurmountable future economic challenges associated with tackling the environmental impacts of the manufacturing industry.

\subsection{Resource Depletion}

In 1980 we exceeded the ecological capacity of our planet and by 2006 we required 1.4 times Earth's capacity to support human activities [4]. It is expected that ageing populations and increasing quality of life in developing countries are likely to push demand far beyond this in the future, adversely affecting the biosphere's regenerative capacity. Even the most modest estimates, based on slow growth and little improvement to lifestyle, predict that human consumption will be twice the Earth's capacity by 2050 [4]. In this context, it is argued that the availability of resources such as raw materials, water and energy, will have a crucial effect on the operation and economics of the manufacturing industry, and in order to better understand this change driver, four main key resources have been explored.

\section{Energy}

By 2050 , it has been estimated that global energy demand will be $80 \%$ higher than today [2]. Furthermore, it has been predicted that over $90 \%$ of this increase in the next 20 years will occur in developing countries where 1.4 billion people have no access to reliable electricity, and more than 2.7 billion people are dependent on traditional bioenergy sources [27]. Of the fuel mix used to meet our current global energy demands, $86 \%$ comes from fossil fuels, the most dominant being oil which accounted for a third of total demands in 2008 [27]. This demonstrates a precarious position as estimates predict that our present oil reserves will be severely depleted by 2050 [2]. More concerning however, is the slow growth of renewable energy production which currently only generates $7 \%$ of total energy demands due to much higher associated costs [27].

\section{Materials}

It is clear that the Earth has a finite amount of material reserves, and it has long been expected that many materials will be in short supply in the near future [5]. The effects of these shortages have already been observed through a rapid rise in the value of scrap steel and other strategically important metals. Furthermore, concerns with supply of rare earths (critical in many renewable energy technologies) are mounting, with a recent U.S. Government report [28] citing that a number of materials are already at high risk, even within the next 5 years. These shifting demands can have significant ramifications as both global supply chains and local economies are greatly dependent upon material availability. The geographic distribution of these materials not only has economic but also political implications, and many countries are critically reliant on trade with others to obtain the materials they require. In order to alleviate the challenges of material shortages, recycling is more frequently being used to recover valuable materials. This however, will not solve the problem as existing technologies are as yet, unable to create a completely closed loop system. A great deal of work is also being conducted into renewable materials such as biopolymers, however, these also need further development to meet existing performance and volume demands [29].

\section{Water}

Salt water accounts for $97.5 \%$ of the water on Earth, with humans predominantly depending on the remaining $2.5 \%$ freshwater, only a fraction of which is readily accessible [30]. At present, around 700 million people live in water stressed areas and 1.1 billion people lack access to safe drinking water. By 2035 , it is estimated that these statistics will rise dramatically with 1 in 3 people living in water stressed areas and climate change causing problems with not only access to drinking water, but also production of food. At present, $70 \%$ of global water consumption is used for agricultural purposes with $22 \%$ for industrial use and $8 \%$ for domestic use [31]. However, significant differences can be observed between developing and developed countries, where in some industrialised countries more than half of abstracted water is utilised by industry. This is almost three times the global average, and highlights the challenges which lie ahead when considering manufacturing activities in water stressed areas. 
Land

It is estimated that around $30 \%$ of global land surface is suitable for crop production, and at present, only $40 \%$ of this is being effectively utilised [32]. The availability of land as a resource will become an area of particular concern as unpredictable weather patterns and changing climates take effect. It is projected that droughts, floods and sea level rises will have significant effects on land availability. For example, in Bangladesh, a rise in sea level of $1 \mathrm{~m}$ could affect 15 million people and submerge $17,000 \mathrm{~km}^{2}$ of land [33]. This highlights the need for a substantial increase in food crop yields to meet the demand of a growing population. This has been exasperated by a rapid growth in use of land for biofuels and biomaterials which are seen as a source of environmentally friendly substitutes for traditional alternatives. In this context, the proposed solution for manufacturing companies to rely on 'solar income' for their energy and material requirements will be a high risk strategy which is highly dependent on land availability.

\section{SMART MANUFACTURING SCENARIOS}

In line with the scenario planning methodology described in the previous sections, the key drivers identified in Section 3 needed to be consolidated into two axes. In this context, it has been recognised that 'population growth' is directly affecting the scale of 'climate change', which epitomises the most concerning issues relating to human impacts on the environment [19]. Thus, these two factors were broadly considered together for the purposes of this study in order to represent the scale of 'environmental impact' of manufacturing activities. This alongside 'resource depletion', which is believed to be the most influential driver for manufacturing industry, formed the two critical axes used to generate the SMS.

The four scenarios created using this method typify the various possible global conditions that the manufacturing industry may face and be required to operate within by the year 2050 . These are depicted in Figure 5 and are labelled as Sustainable Planet (SP), Unsustainable Planet (UP), Technologically Sustained Planet (TSP) and Socio-Economically Sustained Planet (SESP).

The following sections describe each scenario through a number of critical 'lenses' for the manufacturing industry that are affected by these global societal and governmental conditions, including energy production, material availability, resource demand, consumerism, and eco-efficiency of manufacturing technologies.

\subsection{Sustainable Planet (SP)}

In this scenario, low consumerism and significant advances in sustainable technologies have created a planet where human life can thrive under sensible conditions. A circular approach to production and a fully closed loop economy have been realised by a combination of a number of factors such as: public and private investment, holistic global policies supported by appropriate international standards and regulations, new business and economic models that encourage growth without environmental degradation, and a societal shift towards responsible and equitable consumption behaviours.

Manufacturing resources (materials, water and energy) are obtained from renewable sources and the planet operates entirely on 'solar income'. Manufacturing activities take place as close as possible to the source of consumption, and environmental impacts of production processes are continuously monitored and mitigated.

Regular training of the workforce provides flexibility in operations and supports adoption of advanced eco-efficient technologies.

Products are designed to meet real needs in the most efficient way, and are built to last or be upgraded as appropriate. GHG emissions are negligible, so the need for specially designed products to combat the impact of global warming has become redundant.

\subsection{Unsustainable Planet (UP)}

In this scenario, high consumerism and lack of investment in environmental technologies has led to difficult and complex conditions in which manufacturing companies must operate.

Access to all resources (materials, water and energy) is severely limited and fossil fuel reserves have been almost entirely, if not completely, diminished. The cost of access to non-renewable resources and the implementation of severe environmental regulations have created very restrictive, high cost business operating parameters. This significantly influences choices of technologies and pathways to innovation, and means that design, production and marketing of products must be very carefully analysed and planned.

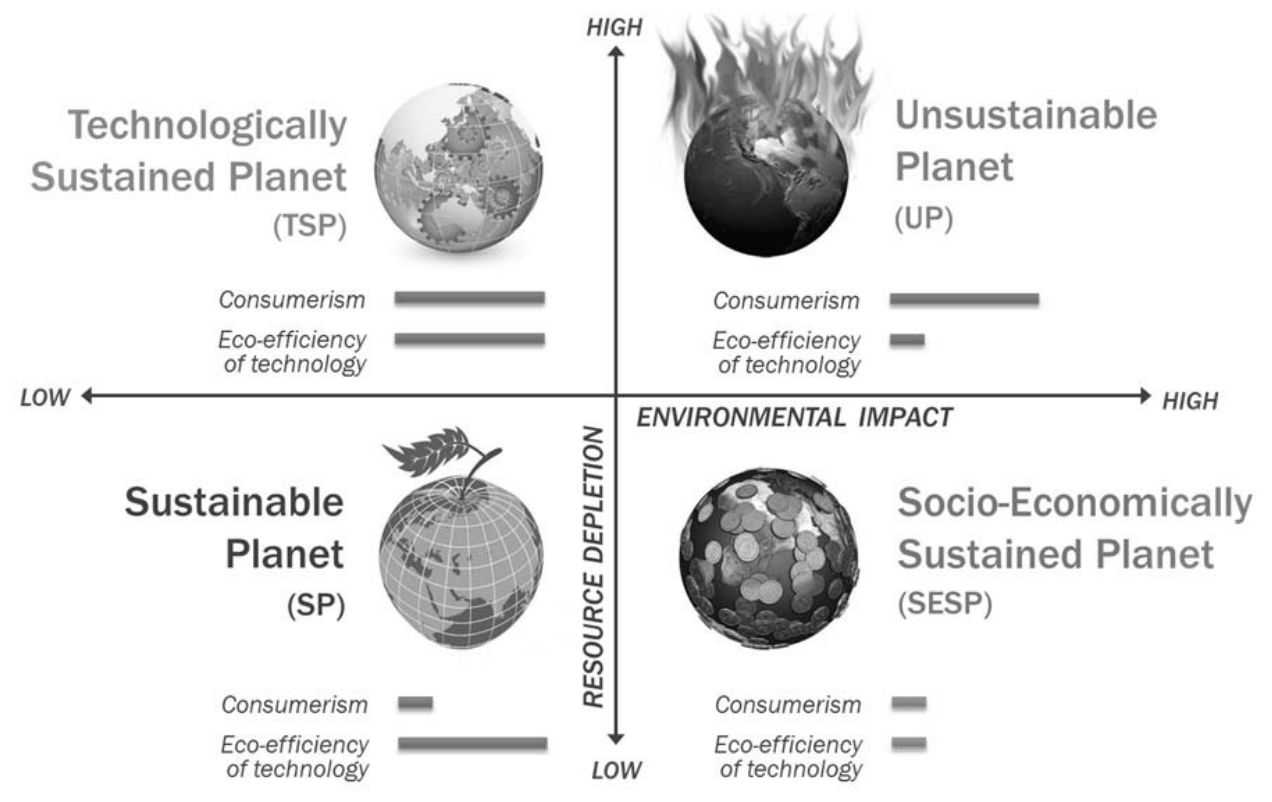

Figure 5: SMART Manufacturing Scenarios 
Due to high demand for access to resources and skills, companies have greater difficulty accessing these from the global market leading societies to develop more independent strategies for 'selfsufficiency'. Localised production has become necessary, not due to environmental benefits, but because of high transport costs, and a lack of willingness to share scarce resources.

Design of products is strongly influenced by a need to combat the ever increasing effects of climate change that have led to variations in localised weather conditions, food production and changes to infrastructure.

\subsection{Technologically Sustained Planet (TSP)}

This scenario describes a planet sustained by vast technological growth and advancements, with environmental impacts controlled by high tech, but resource intensive solutions. Consumerism remains high as this advancement in technology has provided capabilities to produce more and more products with fewer resources, and raised the requirement for highly trained and skilled labour.

These advancements have favourably impacted the availability of resources, and recycling is intensively practiced to recover and recirculate even hard to extract materials. Competitive global trade has accelerated development of global infrastructures and local economies, particularly in resource rich countries; with resource poor countries only able to attract production activities through cheap labour.

Technological and product developments have centred on combating the effects of climate change, for example extensive weather control systems to mitigate the impacts of flooding, droughts and high winds, and production systems to ensure access to food and drinking water across the globe.

\subsection{Socio-Economically Sustained Planet (SESP)}

In this scenario, lack of investment in sustainable technologies has led to the creation of localised insular communities, formed to sustain a lifestyle in which continuous financial crisis has significantly driven down consumption patterns.

Local and/or national coalition groups protect their own resources and look after their own basic needs (e.g. energy and food).
Political alliances are strategic to trade specific resources and global trade is highly limited. Production activities take place locally within these small communities, creating large demand for local flexible labour and cooperation. Rationing, reuse, remanufacturing and recycling are employed to preserve resources, and energy production is limited to readily available solutions.

As consumers are more economically aware, companies require significantly more competitive products and must be strategic about product ranges and selected markets in which they operate. Products need to meet specific local needs and enable efficient, recoverable use of resources.

\section{APPLICATION OF SMART MANUFACTURING SCENARIOS}

Current approaches to lowering the overall environmental impact of a manufacturing company are often built on 'push-based' strategic planning. In such approaches, a number of factors are considered such as regulatory requirements, available investment and skills, consumer pressures, market demand, etc. This aids in development of short term stepwise procedures that deliver modest improvements (e.g. Implementation an Environmental Management System based on ISO14001). The consideration of key drivers (i.e. population growth, climate change and resource depletion) in this paper has made a compelling case that such incremental improvements will not be sufficient to prepare the manufacturing industry for the difficult and complex challenges that will need to be faced in the medium to long term future.

The use of the SMS presents a distinctly different approach built on 'pull-based' strategic planning. This focuses on long term manufacturing objectives in order to deliver and embed the readiness and resilience required to deal with future manufacturing challenges.

While considering long term manufacturing objectives, there are a number of examples (such as improved staff training) that will be beneficial in all four scenarios. However, there are also those that are more supportive for a specific scenario. Figure 6 exemplifies a subset of such objectives for each manufacturing scenarios. Evidently, the range and scope of these objectives will vary depending on the product type, company size, and manufacturing sector.

\begin{tabular}{|c|c|}
\hline TSP & UP \\
\hline $\begin{array}{l}\text { - High investment in advanced technologies. } \\
\text { - Ability to cultivate a culture for product and } \\
\text { process innovation. } \\
\text { - High-tech automated manufacturing that relies } \\
\text { on global sourcing of skills. } \\
\text { - ........ }\end{array}$ & $\begin{array}{l}\text { - Securing access to resources. } \\
\text { - Ability to adhere to a complex mix of } \\
\text { environmental regulations. } \\
\text { - Demand for products that withstand and } \\
\text { combat the effects of a changing climate. } \\
\text { - ........ }\end{array}$ \\
\hline SP & SESP \\
\hline $\begin{array}{l}\text { - Sustainable product design capabilities. } \\
\text { - Ability to operate in the context of extended } \\
\text { producer responsibility. } \\
\text { - Meeting the basic needs of the consumer } \\
\text { through a mix of products and services. } \\
\text { - ........ }\end{array}$ & $\begin{array}{l}\text { - Ability to operate in competitive and restrictive } \\
\text { markets. } \\
\text { - Ability to source resources locally and operate } \\
\text { within insular, smaller communities. } \\
\text { - Demand only for commodity products that meet } \\
\text { specific, basic needs. } \\
\text { - ........ }\end{array}$ \\
\hline
\end{tabular}

Figure 6: Example Objectives for each of the SMART Manufacturing Scenarios 
One other key consideration with regards to the SMS is the inherent loops that may develop between TSP $\leftrightarrow$ UP and SESP $\leftrightarrow$ UP, as illustrated in Figure 7. The loop between TSP $\leftrightarrow$ UP represents a pattern often referred to as the 'rebound effect' in which the ecoefficiency gained through technological advancements and improvements is offset due to significant growth in consumption of the product. This further expands the scope and definition of 'advanced manufacturing' to include considerations for the elimination of the rebound effect, so that the pathway from TSP moves towards SP, as depicted by the dashed arrow between the two in Figure 7.

The loop between SESP $\leftrightarrow$ UP represents the cycle often referred to as a 'boom and bust', in which during an economic crisis the frequently proposed solution is to 'excite the market' and encourage increased consumption through availability of 'disposable income' for consumers. In this context, the improvement in environmental impact during a specific period is wiped out by a period of rapid growth in consumption. The key challenge in such cases is often through sustainable investment in green products and technologies (e.g. renewable energy) and infrastructure improvements that lower environmental impacts (e.g. public transport), therefore producing a path from SESP $\rightarrow$ SP, as depicted by the dashed arrow in Figure 7 .

\section{CONCULDING DISCUSSIONS AND FUTURE WORK}

Manufacturing industry faces a number of critical challenges due to the societal, economic and ecological impacts associated with its activities. The incremental approach currently adopted to lower these impacts will not meet the requirements for long term sustainability of the manufacturing sector. In this context, there is a need to develop strategies supported by stepwise action plans that provide readiness for upcoming challenges and resilience towards future changes.

The SMART Manufacturing Scenarios presented in this paper provide insights in to a number alternative global conditions that a typical manufacturing company may face. It should be noted that these scenarios do not represent four mutually independent possibilities, instead it is envisaged that the planet could easily shift between these different states as economic crises force lower consumption, or new green technologies improve capabilities to lower the ecological footprint.

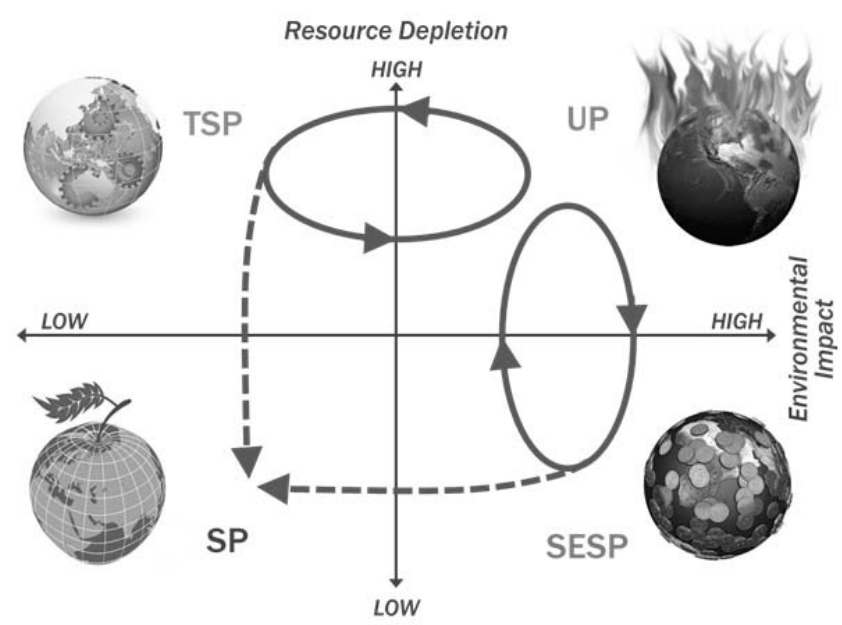

Figure 7: SMART Manufacturing Scenario Loops
In this scenario planning exercise it has been assumed that lower resource use is linked directly to lower consumption, and that improved sustainability is linked to advances in enabling technologies. Such assumptions may need to be revised as we learn to decouple our 'economic growth' from 'environmental degradation', however, at present these assumptions very much represent the reality that has been observed throughout recent decades in both developed and developing countries.

In the further expansion of this research, the principal concepts of this scenario planning exercise are utilised to develop a series of SMART strategic planning tools specifically tailored to the requirements of the manufacturing industry. These aid to identify the most relevant long term objectives for companies of varying sizes, sectors and product ranges. The SMART tools focus on five key common factors which influence manufacturing activities. These are referred to as 'ManuFactors' [34], and include resources, products, production, labour and markets. The ManuFactors are explored as part of the SMART tools to provide strategic direction in order to achieve resilience within the four scenarios identified as part of the SMS.

Finally, it should be noted that although the SMS are developed for the manufacturing industry, they could further be utilised in a range of complementary sectors that will also need to change dramatically in order to secure their long term survival.

\section{REFERENCES}

[1] United Nations (2011); World Population Prospects: The 2010 Revision: Highlights and Advance Tables, UN Department of Economic and Social Affairs: Population Division, New York, U.S.

[2] Organisation for Economic Co-operation and Development (2012); OECD Environmental Outlook to 2050: The Consequences of Inaction, OECD Publishing, Paris, France.

[3] WWF (2011); The Energy Report: 100\% Renewable Energy by 2050, WWF - World Wide Fund For Nature, Gland, Switzerland.

[4] Ewing, B., Goldfinger, S., Oursler, A., Reed, A., Moore, D., Wackernagel, M. (2009); The Ecological Footprint Atlas 2009, Global Footprint Network, Oakland, U.S.

[5] Halada, K., Shimada, M., Ijima, K. (2008); Forecasting of the Consumption of Metals up to 2050, in: Materials Transactions, Vol. 49, pp. 402-410.

[6] Gardner-Outlaw, T., Engleman, R. (1997); Sustaining Water, Easing Scarcity: A Second Update, Population Action International (PAI), Washington DC, U.S.

[7] Wack, P. (1985); Scenarios: Shooting the Rapids, in: Harvard Business Review, November-December 1985.

[8] Wack, P. (1985); Scenarios: Unchartered Waters Ahead, in: Harvard Business Review, September-October 1985.

[9] Shell (2008); Scenarios: An Explorer's Guide, Shell International BV, The Hague, The Netherlands.

[10] Shell (2011); Signals and Signposts: Shell Energy Scenarios to 2050, Shell International BV, The Hague, The Netherlands.

[11] World Business Council for Sustainable Development (1997); Exploring Sustainable Development: Global Scenarios 20002050, WBCSD, London, U.K. 
[12] World Energy Council (2007); Deciding the Future: Energy Policy Scenarios to 2050, WEC, London, U.K.

[13] Department of Trade and Industry (2002); Foresight Futures 2020: Scenarios and User Guidance, DTI, London, U.K.

[14] Demos Helsinki (2011); Scenarios for Sustainable Lifestyles 2050: From Global Champions to Local Loops, UNEP / Wuppertal Institute Collaborating: Centre on Sustainable Consumption and Production (CSCP), Wuppertal, Germany.

[15] Forum for the Future (2008); Climate Futures: Responses to climate change in 2030, Forum for the Future, London, U.K.

[16] Sony (2011); FutureScapes: The Scenarios, Forum for the Future / Sony Europe.

[17] Government Office for Science (2009); Scenario Planning: Guidance Note, Foresight Horizon Scanning Centre, London, U.K.

[18] European Commission (2003); The Future of Manufacturing in Europe 2015-2020: The Challenge for Sustainability, EC Joint Research Centre.

[19] United Nations Environment Programme (2012); Global Environment Outlook 5: Environment for the future we want, UNEP \& Progress Press, Valletta, Malta.

[20] Wikipedia (2012); File:World population (UN).svg, http://en.wikipedia.org/wiki/File:World_population_\%28UN\%2 9.svg, accessed on: 30/01/2013.

[21] Food and Agriculture Organization of the United Nations (2009); More people than ever are victims of hunger, http://www.fao.org/fileadmin/user_upload/newsroom/docs/Pre ss\%20release\%20june-en.pdf, accessed on: 30/01/2013.

[22] United Nations Educational Scientific and Cultural Organization (2006); Water: A Shared Responsibility: The United Nations World Water Development Report 2, UNESCO \& Berghahn Books, New York, U.S.A.

[23] Stern, N. (2007); The Economics of Climate Change: The Stern Review, Cambridge University Press, Cambridge, U.K.

[24] United Nations (2011); Report of the Conference of the Parties on its Sixteenth Session: held in Cancun from 29 November to 10 December 2010, United Nations Framework Convention on Climate Change, Bonn, Germany.

[25] United Nations Environment Programme (2011); Bridging the Emissions Gap, UNEP, Nairobi, Kenya.

[26] United Nations Environment Programme (2012); Global Outlook on Sustainable Consumption and Production Policies: Taking action together, UNEP, Paris, France.

[27] International Energy Agency (2010); World Energy Outlook 2010, OECD/IEA, Paris, France.

[28] U.S. Department of Energy (2010); Critical Materials Strategy, DOE, U.S.

[29] Colwill, J.A., Wright, E.I., Rahimifard, S., Clegg, A.J. (2012); Bio-Plastics in the context of competing demands on agricultural land in 2050, in: International Journal of Sustainable Engineering, Vol. 5, pp. 3-16.

[30] World Resources Institute (2008); Watering Scarcity: Private Investment Opportunities in Agricultural Water Use Efficiency, Rabobank, Utrecht, The Netherlands.
[31] United Nations Educational Scientific and Cultural Organization (2003); Water for People, Water for Life: The United Nations World Water Development Report, UNESCO \& Berghahn Books, New York, U.S.A

[32] Nachtergaele, F., Bruinsma, J., Valbo-Jorgensen, J., Bartley, D. (2011) SOLAW Background Thematic Report - TR01: Anticipated trends in the use of global land and water resources, Food and Agriculture Organization of the United Nations.

[33] United Nations Environment Programme (2008); Vital Water Graphics: An Overview of the State of the World's Fresh and Marine Waters - 2nd Edition, UNEP, Nairobi, Kenya.

[34] Rahimifard, S. (2012); Inaugural Lecture, Iborouniversity, http://youtu.be/9iJX0fxys1A, accessed on: 30/01/2013. 